Эльмира Наберушкина

\title{
ОБЗОР СОЦИАЛЬНЫХ ПРОБЛЕМ ИНВАЛИДНОСТИ В КОНТЕКСТЕ ЗАНЯТОСТИ, СОЦИАЛЬНОЙ ПОЛИТИКИ И СОЦИАЛЬНЫХ ДИСТАНЦИЙ
}

На фоне изменений социальной политики анализируются проблемы занятости и социальной инклюзии людей с инвалидностью. Основной фокус направлен на обзор становления социологического прочтения инвалидности, характеризуются данные о трудоустройстве людей с инвалидностью в условиях социальных проблем, реформ социального законодательства, падения престижа профессии социальной работы в России. Рассмотрение ситуации с трудоустройством людей с инвалидностью осуществляется с привлечением данных всероссийских опросов, где исследовались области ущемления прав инвалидов, их ожидания по поводу собственной занятости. Обращение к исследованиям в рамках качественной методологии прояснило позицию работодателей и показало наиболее уязвимые области трудоустройства инвалидов, а именно - непривлекательность определенных категорий как работников и отсутствие весомых стимулов для работодателя, побуждающих принимать на работу инвалидов. Можно заключить, что в российском обществе к лучшему изменилась ситуация с пониманием проблем инвалидности, умением формировать доступную инфраструктуру социальных услуг и выстраивать социальные коммуникации недискриминационного порядка. В меньшей степени меняется ситуация занятости инвалидов, на рынке труда нарастает напряженность при трудоустройстве людей с инвалидностью. Сохраняются формальные каналы помощи в трудоустройстве через квотирования, однако факты эксклюзии инвалидов на рынке труда скрыты легитимными формулировками отказов в приеме на работу, хотя и фиксируются в случае применения качественной методологии исследования. Социологическое прочтение проблем инвалидности, социальной политики и социальной работы, инициированные крупными научными коллективами, послужили растущему признанию обществом прав людей с инвалидностью, переформатированию дискурса социальной работы, однако ситуация с трудоустройством людей с инвалидностью остается одной из наиболее острых.

Ключевые слова: люди с инвалидностью, социальная политика, социальная работа, трудоустройство, занятость инвалидов

DOI: $10.17323 / 727-0634-2017-15-2-333-340$

В 2010 г. Павлом Романовым и Еленой Ярской-Смирновой опубликована статья, в которой оценивался двадцатилетний этап исследований инвалидности,

Эльмира Кямаловна Наберушкина - д.соц.н., профессор кафедры социальной работы, БелГУ, Белгород, Россия. Электронный адрес: naberushkinaek@gmail.com 
сформулирован концептуальный подход социологического осмысления проблем неравенства и социального исключения по признаку инвалидности на основе оценки социально-политической динамики и колебания социальных дистанций. Сегодня в связи с новыми социально-экономическими вызовами необходим дальнейший анализ изменений политики инвалидности, в том числе в области трудоустройства людей с ограниченными возможностями здоровья. Подобные исследования одновременно становятся вкладом в изменение социальной политики инвалидности: «анализ политики, конечно, не может изменить условия, но может изменить дискурс, способ размышления о той или иной проблеме» (Романов 2003: 61).

Действительно, в результате научно-исследовательской работы дискурс меняется, формируются новые общественные взгляды на различные аспекты инвалидности, происходит акцентуация источников социальной эксклюзии людей с ограниченными возможностями здоровья. Если соотнести современный язык официальных органов и СМИ об инвалидности с прошлым, можно увидеть перемещение способов объяснения инвалидности из области личной ситуации в сферу социальных барьеров и исключающих стратегий. На этапе становления методологии и практики социальной работы этому способствовало создание одного из первых подразделений по подготовке специалистов по социальной работе, где социальная политика инвалидности стала приоритетной сферой исследования, как, например, в политехническом институте Саратова.

Социологическое прочтение инвалидности сформировалось на фоне доминирующего тогда восприятия ее как исключительно медицинской проблемы. Новое видение и исследовательское направление быстро обрело последователей и вызвало серьезную заинтересованность практикующих специалистов социальной сферы, представителей законодательных органов, лидеров общественных движений, журналистов и ученых. Команда саратовских социологов осуществила не только исследовательские, но и акционистские проекты, что стало новым и востребованным трендом эффективного взаимодействия науки и практики. Так, в числе первых проектов социологического осмысления инвалидности были посвященные занятости (ЯрскаяСмирнова 1997; Иванова 2004), культуре (Бойко 1997), социальной политике (Ярская 1998; Ловцова 2002), гендерным аспектам (Ярская-Смирнова 2001), образованию (Зайцев 2001), профессиям (Печенкин 2006), повседневности (Бендина 2005), социальной стратификации (Наберушкина 1999) и другим темам. Широкое распространение результатов исследований и обсуждение научных достижений на междисциплинарных и межведомственных площадках запустило механизм постепенного производства нового видения инвалидности социальными службами, где доминирующими идеями стали инклюзия, права человека, этические и профессиональные принципы социальной работы, признание научно-исследовательской деятельности в качестве определяющей. 
Наряду с обоснованием прогрессивной и успешной модернизации Романов отметил, что практика и риторика социальной работы в России пока не включают аспект социальной справедливости (Романов 2003). Это замечание актуально и сегодня. Так, при рассмотрении тенденций изменений нормативно-законодательной базы в области социальной защиты видно, что вступивший в силу в 2015 г. Федеральный закон № 442-Ф3 оперирует понятиями «социальная услуга», «получатель социальных услуг», «поставщик социальных услуг», «стандарт социальной услуги». Это демонстрирует тенденцию профессионализации социальной работы. Однако при этом из социальной политики исчезло понятие «социальная поддержка», которое позволяло формулировать цели в дискурсе социальной справедливости. В новом законе доминирует категория «услуга», что формирует понимание системы социальной помощи как сферы сервиса, но не позволяет говорить о долгосрочных и филантропических перспективах. Кроме того, из законодательства исключено понятие «муниципальной социальной работы», что означает утрату внимания к стратификации регионов, чреватую территориальной дезинтеграцией и ростом социальной напряженности.

Сегодня продолжается тенденция снижения престижа социальной работы: «система социального обслуживания по сути дела порождает новые формы социального исключения, в том числе, основанные на маргинализации важнейших профессиональных групп - социальных работников и специалистов по социальной работе» (Ярская, Ярская-Смирнова 2002: 81). По состоянию на начало 2017 г. оплата труда социальных работников не превышает 16 тыс. рублей: в Ростовской области - 7,5 тыс. рублей, в Оренбурге только в декабре прошлого года повышена с 5,5 до 8,5 тыс., (Proprof.ru 2017). Проигрывают работники социальной сферы специалистам других отраслей не только в материальном плане, но и в области перспектив карьерного роста. Социальная служба гендерно разбалансирована, основная масса занятых - женщины со значительным кластером специалистов предпенсионного возраста, так как молодых специалистов и выпускников вузов не привлекает уровень заработной платы.

В 2008 г. результаты исследований о правах человека как зоне разногласий фиксировали, что большинство респондентов (55,3\%) полагали: в правах человека нельзя ограничивать никого, однако с оговоркой на допустимость ограничения прав нелегальных мигрантов - 22,1\%, душевнобольных - 23,3\%, несовершеннолетних - 12,5\%, бездомных $-10,8 \%$ и инвалидов - 2,7\% (Белоусова 2008). Всероссийский опрос качества жизни инвалидов в 2011 г. показал, что ущемление прав людей с инвалидностью имеет место в основном в области получения льгот, а хуже всего обстоит дело с льготным лекарственным обеспечением и медицинским обслуживание (ВОИ 2011). В 2012 г. исследования выявили, что доля проявления социальной нетерпимости в обществе значительна: 64,4\% инвалидов заявляли о том, что им приходится слышать оскорбительные 
замечания, сталкиваться с нетерпимым отношением, преодолевать безучастность чиновников в учреждениях; 54,2\% людей с инвалидностью столкнулись с отказом в приеме в учебное заведение; 53,4\% ущемлены в оплате труда; 51 \% получали безосновательный отказ в приеме на работу (Наберушкина 2012). Более ранние исследования, осуществленные с помощью качественной методологии, помогли увидеть эти и другие сферы нарушения прав инвалидов. Так, устные истории информантов позволили выявить стигму двойной дискриминации, которой подвергаются женщины с инвалидностью (Ярская-Смирнова и др. 2007). Ситуация в области трудоустройства женщин с инвалидностью и женщин, имеющих детей инвалидов, одна из самых проблемных и сопряжена с многочисленными отказами в приеме на работу по причине инвалидности.

Анализ проблем занятости выявил не только степень эффективности политики квотирования рабочих мест для инвалидов, но и показал факторы, тормозящие социальные перемены. Установлено, что перспективы интеграции инвалидов в сферу занятости работодатели оценивают скептически по ряду причин, среди которых: внедрение новых технологий, требующих высокой квалификации, сокращение рабочих мест, что приводит к высвобождению сфер, где использовался труд инвалидов (Романов и др. 2009). Исследовательские данные показали предпочтения работодателей в отношении работников без инвалидности в условиях наличия жестких мер контроля за условиями занятости инвалидов и отсутствия стимулов, побуждающих принимать людей с инвалидностью на работу. Система льготного налогообложения для предприятий, использующих труд инвалидов, на тот момент была ликвидирована, хотя опросы ВЦИОМ фиксировали, что большинство $(81,4 \%)$ одобряло этот механизм (ВЦИОМ 2016). Обратившись к данным исследования «Социальная защищенность населения России» (2007 г.) ГУ ВШЭ (число опрошенных 1800) и выбрав соответствующие переменные из базы данных исследования, можно увидеть, что и сами люди с инвалидностью не испытывали иллюзий по поводу доступности занятости в случае потери работы, полагая что не смогут или вероятнее всего не смогут найти работу (Исследование ВШЭ 2007). Если среди людей с нормой здоровья график стремится в сторону оптимистических ожиданий, то среди людей с заболеваниями и инвалидностью ответы имеют противоположную направленность в сторону пессимистических прогнозов (табл. 1).

Сегодня за счет массовых сокращений и высвобождения трудоспособного населения, рынок труда еще больше чем десять лет назад сокращает шансы на трудоустройство инвалидов. В 2016 г. Всероссийский центр изучения общественного мнения представил данные опроса о том, какова на сегодняшний день ситуация с трудоустройством квотируемых категорий (ВЦИОМ 2016). Среди представителей предприятий, где в данный момент не работают инвалиды, $67 \%$ ответивших выражают отрицательное отношение к трудоустройству инвалидов, утверждают, что предприятие не готово 
к их трудоустройству. Предприятия, выполняющие закон о квотировании, почти всегда заявляют о своей готовности и дальше трудоустраивать людей с инвалидностью. Однако москвичей с ограниченными возможностями столичные работодатели трудоустраивают значительно реже, чем выпускников учреждений профессионального образования без инвалидности. Так, инвалиды с заболеваниями опорно-двигательного аппарата представлены в штате $19 \%$ московских фирм, инвалиды по слуху - в $13 \%$, инвалиды по зрению - в 5 \% (ВЦИОМ 2016). Ситуация занятости инвалидов в российских регионах со сниженной инвестиционной активностью и неблагополучной картиной по безработице с каждым годом ухудшается.

Таблийа 1.

Распределение ответов на вопрос, сможете ли Вы найти работу в случае ее потери (по данным исследования ВШЭ «Социальная защищенность населения России»)

\begin{tabular}{|c|c|c|c|c|c|c|}
\hline Сможсте найти работу? & $\Xi$ & 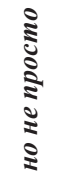 & 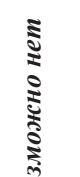 & Е & 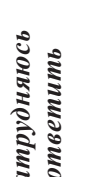 & $\begin{array}{l}\stackrel{\Xi}{\Xi} \\
\Xi \\
\Sigma\end{array}$ \\
\hline Здоровье & & है & if & & & \\
\hline Нет, серьезных проблем нет & 83.1 & 79.9 & 68.6 & 57.3 & 71.7 & 50.4 \\
\hline $\begin{array}{l}\text { Да, серьезное хроническое заболева- } \\
\text { ние }\end{array}$ & 16.2 & 18.0 & 27.9 & 38.5 & 25.2 & 13.8 \\
\hline Да, инвалидность & 0.8 & 2.1 & 3.6 & 4.2 & 3.1 & 1.4 \\
\hline Итого & 100.0 & 100.0 & 100.0 & 100.0 & 100.0 & 100.0 \\
\hline
\end{tabular}

Итак, сопоставленные результаты исследований проблем инвалидности разных лет позволяют предположить, что к лучшему изменилась ситуация с пониманием проблем инвалидности в поле социального гражданства, а готовность общества к изменениям недискриминационного порядка проявляется заметнее в области развития нормативно-законодательной базы, в аспекте формирования инфраструктурной доступности. В меньшей степени меняется ситуация занятости инвалидов. На рынке труда консервируется, а в ряде регионов нарастает напряженность в отношении трудоустройства людей с инвалидностью. Социальные дистанции по отношению к людям с инвалидностью сохраняются, однако факты эксклюзии инвалидов на рынке труда скрыты легитимными формулировками отказов в приеме на работу, хотя и фиксируются в случае применения качественной методологии исследования. Социологические прочтения проблем инвалидности, социальной политики и социальной работы послужили растущему признанию обществом прав 
людей с инвалидностью, переформатированию дискурса социальной работы, однако ситуация с трудоустройством людей с инвалидностью остается.

\section{Выражения благодарности}

Работа поддержана грантом Международной грантовой программы 2016 г. Института перспективных исследований Московского педагогического государственного университета.

\section{Список источников}

Белоусова М. (2008) Права человека как зона разногласий и консенсуса элит и населения. Доступно по ссылке: https:/clck.ru/A4xrf (дата обращения: 28 мая 2016).

Бендина О. А. (2005) Гендерные аспекты повседневных практик лечения. А.С. Борщов (ред.) Основания и парадигмы современного общественного развития, Саратов: Научная книга: 146-149. Бойко О. В. (1997) Социокультурный подход к изучению суицида. Е.Р. Смирнова (ред.) Социокультурные проблемы нетипичности, Саратов: СГТУ: 126-129.

ВОИ (2011) Анализ результатов мониторинга ситуации с обеспечением беспрепятственного доступа инвалидов Российской Федерачии к объектам соииальной инфраструктуры (по состоянию на 1 июля 2011года). Доступно по ссылке: https:/clck.ru/B 7nPo (дата обращения: 3 мая 2017). ВЦИОМ (2016) Соииально уязвимые категории граждан на рынке труда Москвы. Прессвыпуск № 3061. Доступно по ссылке: https://clck.ru/A4xsE (дата обращения: 11 мая 2017).

Зайцев Д. В. (2001) Специальное образование детей с нарушениями интеллекта, Саратов: СГУ. Иванова И.Н. (2004) Рынок труда и рынок образования: как устранить дисбаланс? Высшее образование в России, (7): 3-10.

Исследование ВШЭ (2007) Социальная защищенность населения России. Доступно по ссылке: https://clck.ru/A4y3o (дата обращения: 11 мая 2017).

Ловцова Н.И. (2002) Семейная политика и охрана детства в риторике официальных документов. Е. Ярская-Смирнова, П. Романов (ред.) Социальная политика и соииальная работа в изменяющейся России, М.: ИНИОН РАН: 178-202.

Наберушкина Э. К. (2012) Инвалиды в большом городе: проблемы социального гражданства, М.: Вариант.

Наберушкина Э. К. (1999) Социальные проблемы инвалидности в условиях стратификации современного российского общества. Д. И. Заров (ред.) Управление соииальными системами, Саратов: СГТУ: 52-55.

Печенкин В. В. (2006) Доступность дополнительного образования для молодых инвалидов: по данным опроса в трех городах России. В.П. Барсуков (ред.) Инвалидность в контексте становления гражданского общества в России, Ставрополь: СевКавГТУ: 159-166.

Романов П. В., Ярская-Смирнова Е.Р. (2010) Инвалиды и общество: двадцать лет спустя. Соииологические исследования, (9): 50-58

Романов П. В., Ярская-Смирнова Е.Р., Вайтфилд С., Келли С. (2009) Сочиологическое исследование проблем инвалидности и реабилитации инвалидов в Российской Федерации. Анализ основных результатов исследования, М.: ЦСПГИ.

Романов П.В. (2003) Социальные изменения и социальная политика. Журнал исследований соииальной политики, 1 (1): 45-67.

Ярская В.Н. (1998) Антропология социальной политики. Человеческие pecypcы, (2): 14-18.

Ярская-Смирнова Е., Наберушкина Э., Белозерова Е., Кочетова Т., Чуева Е. (2007) Женщины и инвалидность: опыт дискриминации и преодоления, Саратов: Научная книга; ЦСПГИ.

Ярская В.Н., Ярская-Смирнова Е.Р. (2002)«Не мужское это дело...» гендерный анализ занятости в социальной работе. Социологические исследования, (6): 74-82.

Ярская-Смирнова Е.Р. (2001) Одежда для Адама и Евы: Очерки гендерных исследований, М.: ИНИОН РАН.

Ярская-Смирнова Е.Р. (1997) Социокультурный анализ нетипичности, Саратов: СГТУ.

Proprof.ru (2017) Зарплата соиработника. Доступно по ссылке: https://clck.ru/B 7nRM (дата обращения: 3 мая 2017). 


\title{
Elmira Naberushkina
}

\section{THE SOCIAL PROBLEMS OF DISABILITY IN A CONTEXTS OF EMPLOYMENT, SOCIAL POLICY AND SOCIAL DISTANCE}

\begin{abstract}
Set against a backdrop of a changing social policy, this article offers a review of the employment and social inclusion of people with disabilities. The main focus is further developing the sociological interpretation of disability, which often relies on data regarding the employment levels of people with disabilities. This data emerges within a specific Russian context including social problems, the reform of social legislation and a decline in the prestige of social work as a profession. In examining the employment of people with disabilities we also utilized data from all-Russian surveys, which examined incidents when the rights of disabled people were infringed and considered their expectations in employment. The use of a qualitative approach helped to clarify the position of employers, revealing how difficult it is for disabled people to find work. This is explained in the unattractiveness of certain categories of disabled people to employers and the lack of incentives offered by the state to employ disabled people. It can be concluded that within the Russian society people's understanding of disability has improved, as has the provision of accessible infrastructure in social services and the development of non-discriminatory social interactions. The situation of employment of disabled people is changing to a lesser extent, however, as the labor market remains; if anything there is growing resistance to the idea of employing people with disabilities. Formal channels of assistance in employment through the use of a quota system remain, but in the labour market there is an implicit exclusion of persons with disabilities disguised as legitimate refusal of employment. A sociological interpretation of the problems connected to disability, social policy and social work, supported by major national research teams, has helped to achieve the growing recognition of the rights of people with disabilities in society, thus reformatting the discourse used when talking about social work. Sadly, the situation with regards the employment of disabled people has not changed significantly and remains an acute issue for social policy.
\end{abstract}

Keywords: people with disabilities, social policy, social work, employment of disabled people, science school

DOI: $10.17323 / 727-0634-2017-15-2-333-340$

\section{References}

Belousova M. (2008) Prava cheloveka kak zona raznoglasiy i konsensusa elit i naseleniya [Human Rights as a Zone of Disagreements and Consensus among Elites and the Population]. Available at: https://clck.ru/A4xrf (accessed 28 May 2016).

Bendina O.A. (2005) Gendernye aspekty povsednevnykh praktik lecheniya [Gender Aspects of Everyday Treatment Practices]. A. S. Borshev (eds.) Osnovaniya i paradigmy sovremennogo obshchestvennogo razvitiya [Grounds and Paradigms of Modern Social Development], Saratov: Nauchnaya kniga: 146-149.

Boyko O. V. (1997) Sotsiokul'turnyy podkhod k izucheniyu suitsida [A Sociocultural Approach to the Study of Suicide]. E. R. Smirnova (eds.) Sotsiokul'turnye problemy netipichnosti [Sociocultural Problems of Atypicality], Saratov: SSTU: 126-129.

Elmira Kamalovna Naberushkina - Dr., Professor, Department of social work, Belgorod State University, Belgorod, Russia. Email: naberushkinaek@gmail.com 
Iarskaia V.N. (1998) Antropologiya sotsial'noy politiki [Anthropology of Social Policy]. Chelovecheskie resursy [Human Resources], (2): 14-18.

Iarskaia V.N., Iarskaia-Smirnova E.R. (2002)'Ne muzhskoe eto delo...' gendernyy analiz zanyatosti v sotsial'noy rabote ['Not a Man's Business ...' a Gender Analysis of Employment in Social Work]. Sotsiologicheskie issledovaniya [Sociological Research], (6): 74-82.

Iarskaia-Smirnova E.R. (1997) Sotsiokul'turnyy analiz netipichnosti [Sociocultural Analysis of Atypicality], Saratov: SGTU.

Iarskaia-Smirnova E.R. (2001) Odezhda dlya Adama i Evy: Ocherki gendernykh issledovaniy [Clothes for Adam and Eve: Essays on Gender Studies], Moscow: INION RAN.

Iarskaia-Smirnova E., Naberushkina E., Belozerova E., Kochetova T., Chueva E. (2007) Zhenshchiny i invalidnost': opyt diskriminatsii i preodoleniya [Women and Disability: The Experience of Discrimination and Coping], Saratov: Nauchnaya kniga; TsSPGI.

Issledovaniya VShE (2007) Sotsial'naya zashchishchennost' naseleniya Rossii [Social Security of the Russian Population]. Available at: https://clck.ru/A4y3o (accessed 18 August 2016).

Ivanova I. N. (2004) Rynok truda i rynok obrazovaniya: kak ustranit' disbalans? [The Labor Market and the Education Market: How to Eliminate Imbalances?]. Vysshee obrazovanie $v$ Rossii [Higher education in Russia], (7): 3-10.

Lovtsova N.I. (2002) Semeynaya politika i okhrana detstva v ritorike ofitsial'nykh dokumentov [Family Policy and Child Protection in the Rhetoric of Official Documents]. E. Iarskaia-Smirnova, P. Romanov (eds.) Sotsial'naya politika i sotsial'naya rabota $v$ izmenyayushcheysya Rossii [Social Policy and Social Work in a Changing Russia], Moscow: INION RAN: 178-202.

Naberushkina E.K. (1999) Sotsial'nye problemy invalidnosti v usloviyakh stratifikatsii sovremennogo rossiyskogo obshchestva [Social Problems of Disability in Conditions of Stratification of Modern Russian Society]. D. Zarov (eds.) Upravlenie sotsial'nymi sistemami [Management of Social Systems], Saratov: SGTU: 52-55.

Naberushkina E.K. (2012) Invalidy v bol'shom gorode: problemy sotsial'nogo grazhdanstva [Disabled People in a Big City: Problems of Social Citizenship], Moscow: Variant.

Pechenkin V. V. (2006) Dostupnost' dopolnitel'nogo obrazovaniya dlya molodykh invalidov: po dannym oprosa $\mathrm{v}$ trekh gorodakh Rossii [Accessibility of Additional Education for Young People with Disabilities: According to a Survey in Three Russian Cities]. Invalidnost'v kontekste stanovleniya grazhdanskogo obshchestva $v$ Rossii [Disability in the Context of the Formation of Civil Society in Russia], Stavropol': SevKavGTU: 159-166.

Proprof.ru (2017) Zarplata sotsrabotnika [The Salary of a Social Worker]. Available at: http://www. proprof.ru/stati/careera/pro-zarplatu/zarplata-socrabotnika (accessed 3 May 2017).

Romanov P. V. (2003) Sotsial'nye izmeneniya i sotsial'naya politika [Social Changes and Social Policy]. Zhurnal issledovaniy sotsial'noy politiki [The Journal of Social Policy Studies], 1(1): 45-67.

Romanov P. V., Iarskaia-Smirnova E.R. (2010) Invalidy i obshchestvo: dvadtsat' let spustya [Invalids and the Community: Twenty Years Old]. Sotsiologicheskie issledovaniya [Sociological Research], (9): 50-58.

Romanov P. V., Iarskaia-Smirnova E.R., Vaytfild S., Kelli S. (2009) Sotsiologicheskoe issledovanie problem invalidnosti i reabilitatsii invalidov v Rossiyskoy Federatsii. Analiz osnovnykh rezul'tatov issledovaniya [A Sociological Study of Disability Problems and the Rehabilitation of Disabled People in the Russian Federation. Analysis of the Main Results of the Study], Moscow: TsSPGI.

VOI (2011) Analiz rezul 'tatov monitoringa situatsii s obespecheniem besprepyatstvennogo dostupa invalidov Rossiyskoy Federatsii k ob"ektam sotsial'noy infrastruktury (po sostoyaniyu na 1 iyulya 201lgoda) [Analysis of the Results of the Monitoring of the Situation with the Provision of Unhindered Access for Disabled People of the Russian Federation to Social Infrastructure Facilities (as of July 1, 2011)]. Available at: http://www.voi.ru/monitoring/monitoring/2011. html (accessed 3 may 2017).

VTsIOM (2016) Sotsial'nouyazvimye kategorii grazhdan na rynke truda Moskvy [Socially Vulnerable Category of the People in the Market of the City of Moscow]. Available at: https://clck. ru/A4xsE (accessed 24 May 2016).

Zaytsev D. V. (2001) Spetsial'noe obrazovanie detey s narusheniyami intellekta [Special Education for Children with Intellectual Disabilities], Saratov: SGU. 